\title{
Разнообразие листовых параметров у прибрежно-водных растений Монголии
}

\section{Diversity of leaf traits in wetland plants of Mongolia}

\author{
Ронжина Д. А. ${ }^{1,2}$, Иванов Л. А. ${ }^{1,2}$, Иванова Л. А., ${ }^{1,2}$ \\ Ronzhina D. A. ${ }^{1,2}$, Ivanov L. A. ${ }^{1,2}$, Ivanova L. A. ${ }^{1,2}$ \\ ${ }^{1}$ Ботанический сад УрО РАН, г. Екатеринбург, Россия. E-mail: Dina.Ronzhina@botgard.uran.ru \\ ${ }^{2}$ Тюменский государственный университет, г. Тюмень, Россия \\ ${ }^{1}$ Institute Botanic Garden, Ural Branch of the Russian Academy of Sciences, Yekaterinburg, Russia \\ ${ }^{2}$ Tyumen State University, Tyumen, Russia
}

Peфepam. Изучены функциональные листовые параметры у 15 видов растений ветландов в лесостепной зоне Монголии. Показано, что у прибрежно-водных растений наиболее вариабельными были показатели размера листовой пластинки (длина и площадь листа), наименее вариабельными - содержание сухого вещества (LDMC) и воды (LWC) в листе, промежуточное положение занимали сухой вес единицы площади листа (LMA), толщина и плотность листа. В среднем однодольные виды имели в 3 раза более толстые листья с большей в 11 раз площадью и в 2 раза большим LMA, чем двудольные. Сравнительный анализ листовых параметров у прибрежно-водных растений ветландов и зональных травянистых растений лесостепной зоны, показал, что интразональные и зональные растения сходны по толщине листа. В то же время листья прибрежно-водных растений отличались от зональных меньшим LMA вследствие низкого содержания сухого вещества в листе, что связано с развитием аэренхимы у растений ветландов.

Ключевые слова. Листовые параметры, Монголия, площадь и толщина листа, растения ветландов, УППЛ.

Summary. Functional leaf traits were studied for 15 species of wetland plants in the forest-steppe zone of Mongolia. It is shown that the leaf length and area were the most variable parameters, the leaf dry matter content (LDMC) and leaf water content (LWC) were the least variable, the leaf mass per area (LMA), leaf thickness and density were intermediate. On average, monocotyledonous species had 3 times thicker leaves with a larger 11 times the leaf area and 2 times larger LMA than dicotyledons. A comparative analysis of leaf parameters in wetland plants and zonal herbaceous plants of the forest-steppe zone showed that intrazonal and zonal plants are similar in leaf thickness. At the same time, the leaves of wetland plants differed from the zonal ones by a lower LMA due to the low LDMC, which is associated with the development of aerenchyma in wetland plants.

Key words. Leaf traits, leaf area and thickness, LMA, Mongolia, wetland plants.

Исследования функциональных параметров листьев растений Монголии традиционно сосредоточены на видах, входящих в состав зональных типов сообществ (Гамалей, Шийрэвдамба, 1988; Слемнев, 1988; Иванов и др., 2004, 2007, 2009; Иванова и др., 2012, Ivanova et al., 2018) и связаны с выявлением механизмов адаптации фотосинтетического аппарата к функционированию в семи-аридных и аридных условиях. Мало изученными в этом отношении являются интразональные прибрежно-водные растения ветландов (переувлажненных территорий с водонасыщенным грунтом), которые также подвергаются воздействию неблагоприятных факторов аридного климата, таких как высокая инсоляция и температура, низкая влажность воздуха. Исследования растений ветландов в условиях гумидного климата показали, что надводные листья макрофитов имеют большое структурное и физиологическое сходство с родственными видами наземных растений (Некрасова и др., 1998, 2003; Ронжина, Пьянков, 2001б; Wetzel, 2001). В то же время, водные растения отличались от наземных из тех же климатических 
условий более толстой листовой пластинкой с развитой аэренхимой, низким сухим весом единицы площади листа и содержанием углерода в 1 г сухого веса листа, большей долей фотосинтетических тканей (Ронжина, Пьянков, 2001a; Ронжина и др., 2009). Задачей нашей работы было изучить разнообразие листовых параметров прибрежно-водных растений Монголии и сравнить значения этих параметров у растений ветландов и зональных типов сообществ.

Исследования функциональных листовых параметров были проведены на 15 видах растений ветландов в лесостепной зоне Монголии на р. Орхон около п. Шамар и на ручье около п. Борнур (табл. 1). Среди изученных видов прибрежно-водных растений большинство (10 из 16) были двудольными покрытосеменными, 7 из этих видов принадлежали к экологической группе гигрофитов, и 3 вида были гидрофитами, наземные формы которых произрастали в прибрежной зоне ветландов. Среди 6 видов однодольных покрытосеменных 5 видов принадлежали к экологической группе гелофитов, и 1 вид был мезофитом.

Таблица 1

Эколого-биологические характеристики изученных видов прибрежно-водных растений Монголии и места их сбора

\begin{tabular}{|l|c|c|c|c|}
\hline \multicolumn{1}{|c|}{ Species } & Class & Life Form & Ecol. Group & $\begin{array}{c}\text { Sampling } \\
\text { site }\end{array}$ \\
\hline Alisma plantago-aquatica L. & $\mathrm{M}$ & $\mathrm{HP}$ & $\mathrm{Hel}$ & 2 \\
\hline Androsace filiformis Retz. & $\mathrm{D}$ & $\mathrm{TP}$ & $\mathrm{Hyg}$ & 1 \\
\hline Callitriche palustris L. & $\mathrm{D}$ & $\mathrm{TP}$ & $\mathrm{Hyd}$ & 1 \\
\hline Echinochloa crusgalli (L.) Beauv. & $\mathrm{M}$ & $\mathrm{TP}$ & $\mathrm{Mes}$ & 2 \\
\hline Epilobium fastigiato-ramosum Nakai & $\mathrm{D}$ & $\mathrm{HCP}$ & $\mathrm{Hyg}$ & 1 \\
\hline Mentha arvensis L. & $\mathrm{D}$ & $\mathrm{HCP}$ & $\mathrm{Hyg}$ & 2 \\
\hline Persicaria amphibia (L.) S.F. Grey & $\mathrm{D}$ & $\mathrm{HCP}, \mathrm{HP}, \mathrm{HDP}$ & $\mathrm{Hyd}$ & 2 \\
\hline Persicaria hydropiper (L.) Delarbre & $\mathrm{D}$ & $\mathrm{TP}$ & $\mathrm{Hyg}$ & 2 \\
\hline Phragmites australis (Cav.) Trin.ex Steud. & $\mathrm{M}$ & $\mathrm{HP}$ & $\mathrm{Hel}$ & 2 \\
\hline Ranunculus natans C.A. May & $\mathrm{D}$ & $\mathrm{HP}, \mathrm{HDP}$ & $\mathrm{Hyd}$ & 1 \\
\hline Rorippa palustris (L.) Bess. & $\mathrm{D}$ & $\mathrm{TP}$ & $\mathrm{Hyg}$ & 1 \\
\hline Scirpus orientalis Ohwi & $\mathrm{M}$ & $\mathrm{HP}$ & $\mathrm{Hel}$ & 2 \\
\hline Sparganium stoloniferum Buch-Ham. ex Graebn. & $\mathrm{M}$ & $\mathrm{HP}$ & $\mathrm{Hel}$ & 2 \\
\hline Stellaria crassifolia Ehrh. & $\mathrm{D}$ & $\mathrm{HCP}$ & $\mathrm{Hyg}$ & 1 \\
\hline Stellaria palustris Retz. & $\mathrm{D}$ & $\mathrm{HCP}$ & $\mathrm{Hyg}$ & 1 \\
\hline Typha laxmannii Lepech. & $\mathrm{M}$ & $\mathrm{HP}$ & $\mathrm{Hel}$ & 2 \\
\hline
\end{tabular}

Примечание. Class (класc): M - Monocotyledones, D - Dicotylédones; Life Form (жизненная форма): ТP - therophyte (терофит), HDP - hydrophyte (гидрофит), HP - helophyte (гелофит), НCР - hemicryptophyte (гемикриптофит); Ecol. Group (экологическая группа): Hyd - hydrophyte (гидрофит), Hel - helophyte (гелофит), Hyg - hygrophyte (гигрофит), Mes - mesophyte (мезофит), Sampling site (место сбора): 1 - untitled stream near Bornur Village (ручей около п. Борнур); 2 - Orchon River near Shamor Village (p. Орхон около п. Шамар).

На свежесобранных листьях измеряли толщину листа с помощью цифрового микрометра РК1012E (Mitutoyo Corp., Япония). Затем листья фотографировали, высушивали и взвешивали. Длину и площадь отдельного листа определяли с помощью системы цифрового анализа изображений Simagis Mesoplant (ООО «СИАМС», Россия). Используя измеренные параметры (площадь, толщина, сырой и сухой вес листа), рассчитывали сухой вес единицы площади листа (LMA, leaf mass per area), плотность листа, содержание сухого вещества (LDMC, leaf dry matter content) и воды (LWC, leaf water content) в листе. В соответствии с общепринятыми представлениями функциональные показатели листьев определяли в пяти биологических повторностях. 
Проведенные исследования показали, что у прибрежно-водных растений наиболее вариабельными были параметры, связанные с размерами листовой пластинки (длина и площадь листа) (табл. 2), наименее вариабельными - LDMC и LWC, промежуточное положение занимали LMA, толщина и плотность листа. Длина листа изменялась у однодольных растений от 11 см у Alisma plantago-aquatica до 91 см Sparganium stoloniferum, у двудольных от 1 см Androsace filiformis до 11 см Persicaria amphibia. Площадь листа была наиболее вариабельным показателем как у двудольных, так и у однодольных видов (табл. 2). В среднем однодольные виды имели в 12 раз более длинные листья с большей в 11 раз площадью, чем двудольные. Толщина листа была параметром, уровень варьирования которого максимально различался между двумя группами: у двудольных видов этот параметр был наиболее стабильным, а у однодольных - сильно варьировал (табл. 2). LMA изменялся у однодольных растений от 340 мг/дм² у Echinochloa crusgalli до 1130 мг/дм² Typha laxmannii, у двудольных от 160 мг/дм² у Callitriche palustris до 630 мг/дм² у Persicaria hydropiper. В среднем однодольные виды имели более толстые (в 3 раза) листья с большим в 2 раза LMA, чем двудольные.

Таблица 2

Средние значения со стандартной ошибкой и коэффициенты вариации листовых параметров у двудольных и однодольных видов прибрежно-водных растений Монголии

\begin{tabular}{|c|c|c|c|c|c|c|c|c|}
\hline \multirow[b]{2}{*}{ Class } & \multirow[b]{2}{*}{ Statistic parameter } & \multicolumn{7}{|c|}{ Leaf parameters } \\
\hline & & $\begin{array}{c}\text { Length, } \\
\mathrm{cm}\end{array}$ & $\begin{array}{c}\text { Area, } \\
\mathrm{cm}^{2}\end{array}$ & $\begin{array}{c}\text { Thick, } \\
\text { mkm }\end{array}$ & $\begin{array}{l}\text { LMA, } \\
\mathrm{mg} / \mathrm{dm}^{2}\end{array}$ & $\begin{array}{l}\text { Density, } \\
\mathrm{g} / \mathrm{cm}^{3}\end{array}$ & $\begin{array}{l}\text { LDMC, } \\
\mathrm{mg} / \mathrm{g} \mathrm{FW}\end{array}$ & $\begin{array}{l}\text { LWC, } \\
\text { g/g DW }\end{array}$ \\
\hline \multirow{3}{*}{$\mathrm{D}$} & Average & $3.7 a$ & $5.1 a$ & $178 \boldsymbol{a}$ & $312 a$ & $0.182 a$ & $211 a$ & $4.3 a$ \\
\hline & Standart error & 1.1 & 3.0 & 15 & 47 & 0.026 & 212 & 0.6 \\
\hline & Coefficient of variation & 30 & 58 & 7 & 15 & 14 & 10 & 14 \\
\hline \multirow{3}{*}{ M } & Average & $44 \boldsymbol{b}$ & $57 \mathrm{~b}$ & $541 \boldsymbol{b}$ & $629 b$ & $0.149 a$ & $253 a$ & $3.3 a$ \\
\hline & Standart error & 11 & 18 & 149 & 124 & 0.038 & 36 & 0.5 \\
\hline & Coefficient of variation & 25 & 32 & 28 & 20 & 25 & 14 & 15 \\
\hline
\end{tabular}

Примечание. Class (класc): M - Monocotyledones, D - Dicotylédones; Leaf parameters (листовые параметры): Length - leaf leangth (длина листа), Area - leaf area (площадь листа), Density - leaf density (плотность листа), Thick - leaf thickness (толщина листа), LMA - leaf mass per area (сухой вес единицы площади листа), LDMC - leaf dry matter content (содержание сухого вещества), LWC - leaf water content (содержание воды), FW - fresh weight (сырой вес), DW - dry weight (сухой вес). Буквы рядом со средними значениями показателей обозначают достоверность отличий по критерию Стьюдента при $p<0.05$.

Сравнительный анализ полученных нами значений листовых параметров у прибрежно-водных растений ветландов и зональных травянистых растений лесостепной зоны, взятых из работы Ivanova et al. (2018), показал, что интразональные и зональные растения сходны по толщине листа (50 \% модальный класс от 200 до 500 мкм). В то же время листья прибрежно-водных растений отличались меньшим LMA (50 \% модальный класс от 300 до 600 мг/дм² у прибрежно-водных против от 500 до 1000 мг/дм² у зональных) вследствие меньшего содержания сухого вещества в листе (50\% модальный класс от 150 до 250 мг/г у прибрежно-водных против от 250 до 400 мг/г у зональных). При одинаковой толщине листа у зональных и интразональных растений низкие значения LMA и LDMC у последних свидетельствовали о развитии межклеточного воздушного пространства (аэренхимы) в листьях прибрежно-водных растений.

Сделано заключение, что у прибрежно-водных растений лесостепной зоны Монголии наиболее вариабельными были параметры размера листовой пластинки (длина и площадь листа), а менее изменчивы - функциональные показатели листьев LMA и LDMC, которые отражают адаптацию фотосинтетического аппарата к аридности климата и локальным условиям местообитания.

Благодарности. Работа выполнена в рамках госзадания Ботанического сада УрО РАН, а также при частичной финансовой поддержке РФФИ 17-29-05019 и 19-54-53015. 


\section{ЛИТЕРАТУРА}

Гамалей Ю. В., Шийрэвдамба Ц. Структурные типы пустынных растений // Пустыни Заалтайской Гоби: характеристика растений-доминантов. - Л.: Наука, 1988. - С. 45-66.

Иванов Л. А., Иванова Л. А., Ронжина Д. А. Закономерности изменения удельной плотности листьев у растений Евразии вдоль градиента аридности // Доклады Академии наук, 2009. - Т. 428. - С. 135-138.

Иванов Л. А., Иванова Л. А., Ронжина Д. А., Циглер Х., Дайгеле К., Гунин П. Д., Пьянков В. И. Влияние межвидовой конкуренции на функциональные свойства растений в горно-степных сообществах Гоби // Экология, 2007. - T. 38. - C. $155-160$.

Иванов Л. А., Ронжина Д. А., Иванова Л. А., Белоусов И. В., Чечулин М. Л., Гунин П. Д., Пьянков В. И. Структурно-функциональные особенности адаптации растений Гоби к аридизации климата // Аридные экосистемы, 2004. - Т. 10. - С. 90-102.

Иванова Л. А., Иванов Л. А., Ронжина Д. А., Церенханд Г., Цоож Ш., Бажа С. Н. Листовые параметры и биомасса кустарников лесостепи Монголии в связи с их экологическими свойствами // Аридные экосистемы, 2012. - T. 18. - C. 60-71.

Некрасова Г. Ф., Ронжина Д. А., Коробицына Е. Б. Формирование фотосинтетического аппарата в период роста погруженного, плавающего и надводного листа гидрофитов // Физиология растений, 1998. - Т. 45. - С. 539-548.

Некрасова Г. Ф., Ронжсина Д. А., Малева М.Г., Пьянков В. И. Фотосинтетический метаболизм и активность карбоксилирующих ферментов у надводных, плавающих и погруженных листьев гидрофитов // Физиология растений, 2003. - Т. 50. - С. 65-75.

Ронжина Д.А., Иванов Л.А., Ламберс Г., Пьянков В.И. Изменение химического состава листьев гидрофитов при адаптации к водной среде // Физиология растений, 2009. - Т. 56. - С. 359-402.

Ронжина Д. А., Пьянков В. И. Структура фотосинтетического аппарата листа пресноводных гидрофитов: I. Общая характеристика мезофилла листа и сравнение с наземными растениями // Физиология растений, 2001a. T. 48. - C. 661-669.

Ронжина Д. А., Пьянков В. И. Структура фотосинтетического аппарата листа пресноводных гидрофитов: II. Количественная характеристика мезофилла листа и функциональная активность листьев с разной степенью погружения // Физиология растений, 2001б. - Т. 48. - С. 836-845.

Слемнев Н. Н. Максимальная фотосинтетическая способность растений // Пустыни Заалтайской Гоби: характеристика растений-доминантов. - Л.: Наука, 1988. - С. 173-180.

Ivanova L. A., Ivanov L. A., Ronzhina D. A., Yudina P. K., Migalina S. V., Shinehuu T., Tserenkhand G., Voronin P. Yu., Anenkhonov O. A., Bazha S. N., Gunin P. D. Leaf traits of C3- and C4-plants indicating climatic adaptation along a latitudinal gradient in Southern Siberia and Mongolia // Flora, 2018. URL: https://doi.org/10.1016/j.flora.2018.10.008

Wetzel R. G. Limnology. Lake and River Ecosystems. - San Diego: Academic Press, 2001. - 678 p. 